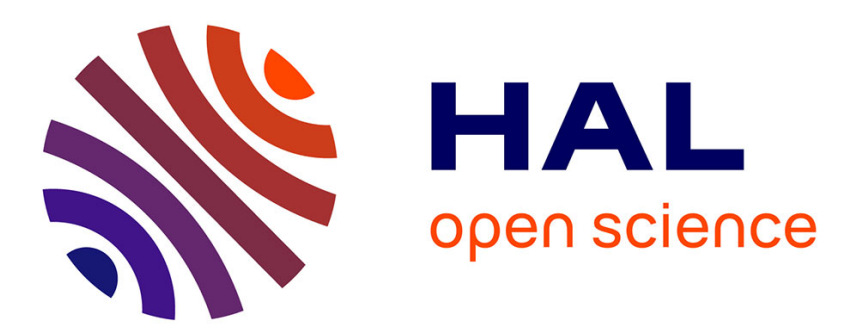

\title{
Carrier suppression system to measure phase noise of acoustic resonators with low motional resistance
}

\author{
Alok Pokharel, Etienne Vaillant, Joël Imbaud, Jean-Jacques Boy, François
}

Xavier Esnault, Fabrice Sthal

\section{To cite this version:}

Alok Pokharel, Etienne Vaillant, Joël Imbaud, Jean-Jacques Boy, François Xavier Esnault, et al.. Carrier suppression system to measure phase noise of acoustic resonators with low motional resistance. Review of Scientific Instruments, 2020, 91 (8), pp.085104 (8). hal-03053109

\author{
HAL Id: hal-03053109 \\ https://hal.science/hal-03053109
}

Submitted on 10 Dec 2020

HAL is a multi-disciplinary open access archive for the deposit and dissemination of scientific research documents, whether they are published or not. The documents may come from teaching and research institutions in France or abroad, or from public or private research centers.
L'archive ouverte pluridisciplinaire HAL, est destinée au dépôt et à la diffusion de documents scientifiques de niveau recherche, publiés ou non, émanant des établissements d'enseignement et de recherche français ou étrangers, des laboratoires publics ou privés. 


\title{
Carrier suppression system to measure phase noise of acoustic resonators with low motional resistance
}

\author{
A. Pokharel, ${ }^{1}$ E. Vaillant, ${ }^{1}$ J. Imbaud, ${ }^{1}$ J.J. Boy, ${ }^{1}$ F. X. Esnault, ${ }^{2}$ and F. Sthal,,${ }^{1, a}$ \\ ${ }^{1}$ FEMTO-ST Institute, Univ. Bourgogne Franche-Comté, CNRS, ENSMM, Besançon, 25000, France \\ ${ }^{2}$ Microwave, Digital \& Optic Dept., Centre National d'Etudes Spatiales, Toulouse, 31400, France
}

A carrier suppression system is implemented in order to measure the phase noise of acoustic resonators that have a low motional resistance. Special adapters' system using transformers is proposed to improve the loaded quality factor of the resonators. With this developped device and described protocol, the inherent noise of resonators can be obtained without an usual electronical oscillator conditionning that could take part in the results. The loaded quality factor is improved from about 10 to 60 percent of the intrinsic quality factor. As an example, the system is used to study Langatate crystal resonators vibrating at $10 \mathrm{MHz}$. Langatate crystal can be an alternative to substitute the quartz crystal resonators for frequency and time applications. Its coupling coefficient and the product quality factor-frequency is normally higher than in quartz crystal resonators. For ultrastable resonators, the motional resistance obtained with Langatate crystal is about five times lower than for the quartz crystal, it can reach typically few ohms. These resonators have been characterized in terms of impedance, Qfactors, turnover temperature, amplitude-frequency effect, and phase noise. The short-term stability of these resonators is given in terms of Allan standard deviation. Influence of the driving power is presented.

\section{INTRODUCTION}

Carrier suppression techniques to measure phase noise were demonstrated by K. H. Sann ${ }^{1}$ in 1968 and then by C. H. Horn ${ }^{2}$ in 1969. Several configurations in metrology applications have been proposed by F. Walls. ${ }^{3}$ These techniques have been used in the microwave band, along with some modifications and improvements. ${ }^{4,5}$ Characterization of quartz crystal resonators with this kind of system started in the beginning of $2000{ }^{6,7}$ The inherent phase stability of crystal resonators is measured in a passive circuit without the noise usually associated with the active oscillator. Conversion of phase noise into short-term stability has been adjusted in $2013 .^{8}$ The interesting part of this measurement method is to give a very low noise floor around $-150 \mathrm{dBc} / \mathrm{Hz}$ at $1 \mathrm{~Hz}$ and $-160 \mathrm{dBc} / \mathrm{Hz}$ at $10 \mathrm{~Hz}$ depending on the driving power of the resonators. In the last decade, the measurements of ultrastable quartz crystal resonators have been performed in order to find explanation on the origin of the $1 / f$ flicker noise., 10 Comparison of different piezoelectric materials could have a great interest in this quest. This method brings an answer about 
the absolute noise that could be reached by the overall oscillator. Until now, the usual studied quartz crystal resonators always had a motional resistance higher than the classical fifty ohms used in all bench components. Then, the loaded quality factor of the resonators observed in the measurement system can easily exhibit fifty to sixty percent of the unloaded quality factor as when it is inserted in the sustaining electronic. It is not the case using Langatate crystal $\left(\mathrm{La}_{3} \mathrm{Ga}_{5.5} \mathrm{Ta}_{0.5} \mathrm{O}_{14}\right)$ also called LGT. ${ }^{11}$ The first $10 \mathrm{MHz}$ ultrastable LGT oscillators whose fractional frequency stability and noise almost similar to quartz oscillators i.e. $10^{-13}$ and $-110 \mathrm{dBc} / \mathrm{Hz}$ at $1 \mathrm{~Hz}$ were published in $2008 .^{12}$ First attempt to measure the phase noise of LGT resonators in a passive way i.e. without an oscillator was done in 2010 but with low-level performance resonators. ${ }^{13,14}$ In this paper, resonators vibrating at $10 \mathrm{MHz}$ are built with very high quality LGT crystal and have been measured on an advanced phase noise measurement system. Because of an impedance value lower than $10 \Omega$ at the resonance, special adaptation was done using transformers to maximize the loaded Q-factor. The impedance bridges have been simulated using an advance optimization process with a simulator in Pspice. Previously, the resonators were characterized in terms of impedance, turnover temperature, and amplitude-frequency effect. The resulting short-term stability of the resonators measured on their metrological vibrating $\mathrm{C}$-mode at $10 \mathrm{MHz}$ is reported according to the resonator driving current. With this developped device and described protocol, the inherent noise of resonators can be obtained without an usual electronical oscillator conditionning that could take part in the results.

\section{PHASE NOISE MEASUREMENT SYSTEM}

\section{A. Principle of the bench}

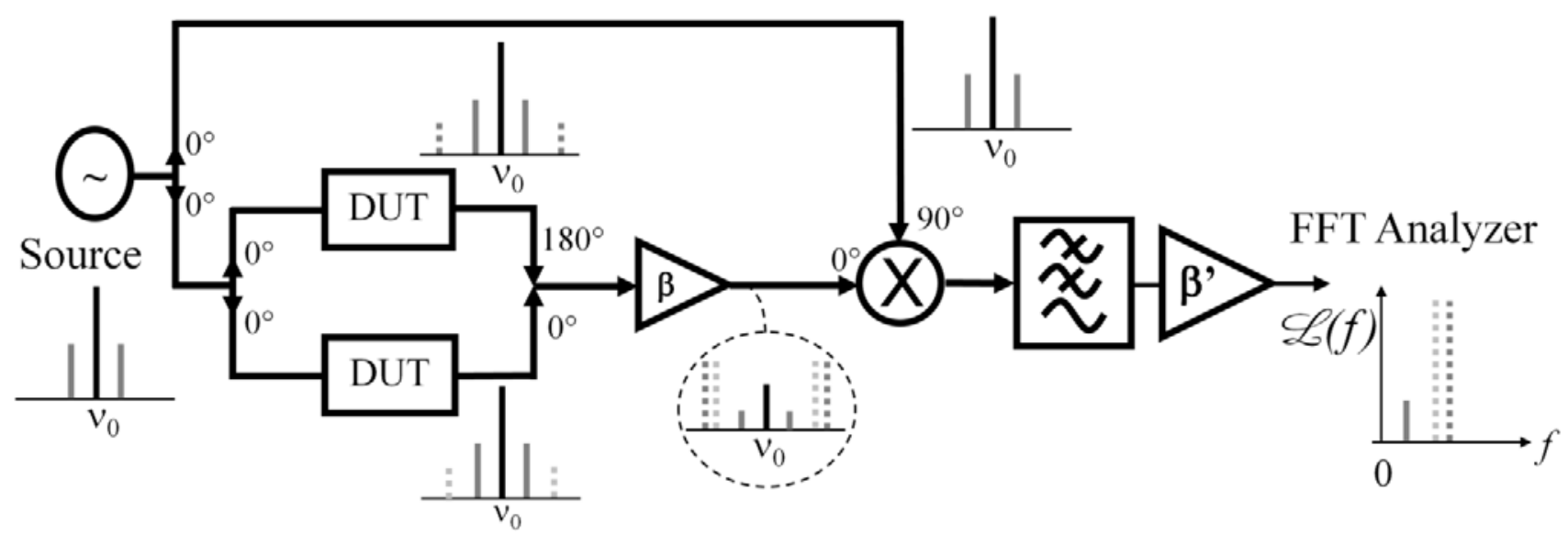

FIG. 1. Principle scheme of the measurement system (DUT: Device Under Test). 
Figure 1 shows the principle of the measurement system. The low noise excitation source is divided in two parts by a first $0^{\circ}$ power splitter. Then, a second $0^{\circ}$ power splitter delivers an equal amount of power in both arms. Both arms of the bridge with the Device Under Test (DUT) have similar arrangement of components. Each arm has a phase shifter and an attenuator to adjust the $180^{\circ}$ shift to complete the carrier suppression. RF low noise amplifier increases the noise of the DUT while its $1 / f$ is maintained at a low level because of the carrier suppression. With a symmetrical mount, the influence of the carrier source is highly reduced. The only remaining fluctuations in output signal would be the noise from the DUT's. Then, a mixer and a low pass filter keeps only the low frequency baseband. Finally, a low noise amplifier increases the output signal that is fed to the FFT analyzer to observe the power spectral density of phase fluctuations. Figure 2 presents the experimental mount.

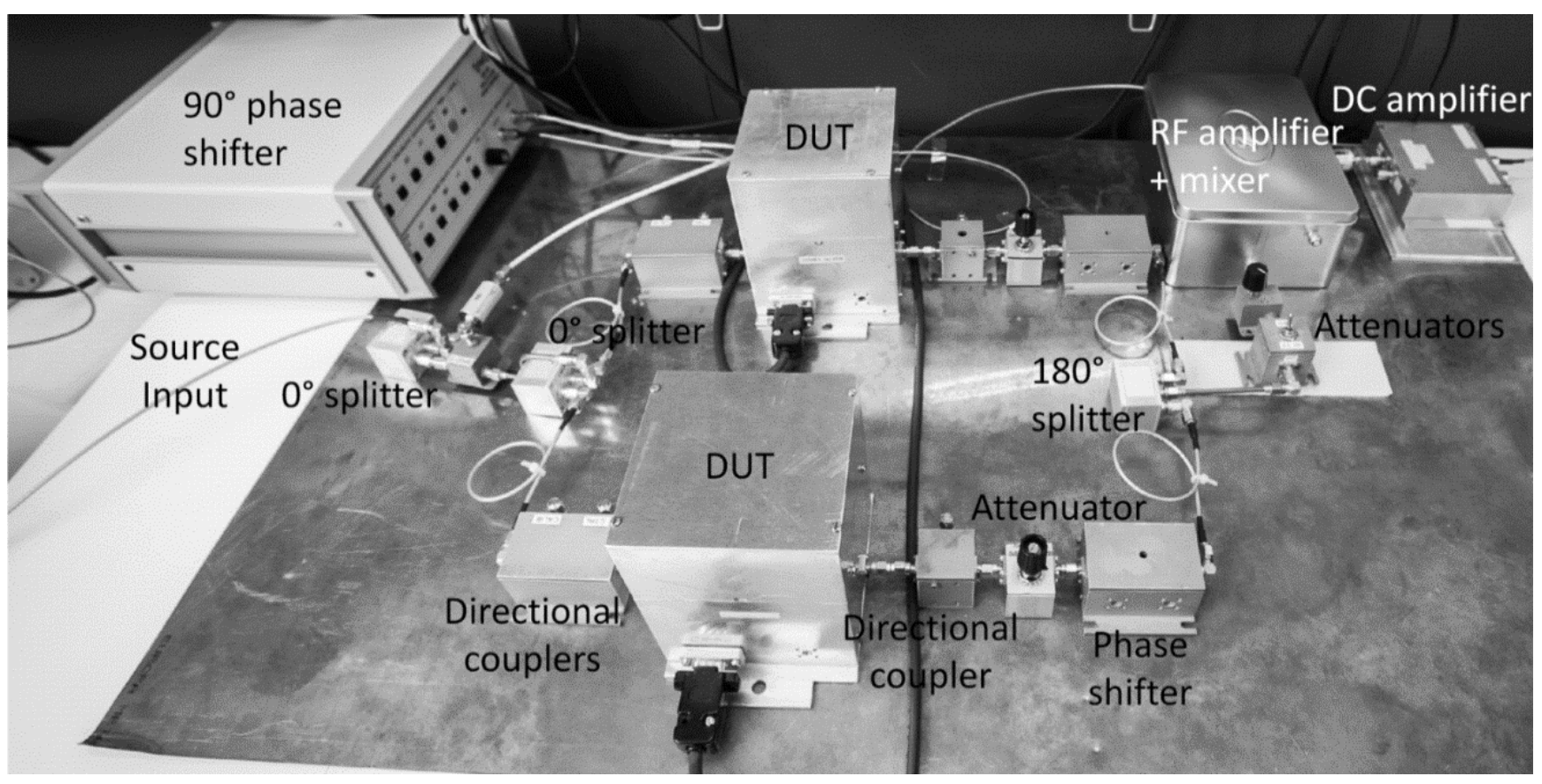

FIG. 2. Phase noise measurement system.

The DUT boxes are temperature controlled in order to get thermal stability when resonators are measured. ${ }^{15,16}$ The thermal stability is around $2 \mu \mathrm{K}$ over a $1 \mathrm{~s}$ period of time in the heart of the oven. Calibration of the measurement system is obtained by injecting a known sideband on one of the arms of the bridge. The result of the measurement bench is corrected using the calibration factor determined from this sideband.

This bench is essentially used to perform measurements near the carrier, generally until $100 \mathrm{kHz}$ to $1 \mathrm{MHz}$, farther the DUT noises from the carrier, more it's possible to be hidden by the noise floor of the bench. That is why this bench is 
particularly well adapted to measure high (loaded) quality factor resonators which have frequency corner (bandpass filter frequency) relatively low and near the carrier.

\section{B. Device under test (DUT)}

\section{Classical DUT configuration}

All the commercial components of the bench are matched at $50 \Omega$. Usually, the measured resonators are matched to $50 \Omega$ using a half $\pi$-bridge build with two external resistor $R_{s}$ and $R_{p}$ (Figure 3 ). The device under tests can possibly be resistors or a pair of crystal resonator to get the noise floor of the system. Resonators are usually associated with a serial capacitor to tune the frequency shift. This configuration is well adapted to resonators that has a motional resistance higher than $50 \Omega$, usually a case for the quartz crystal resonators.

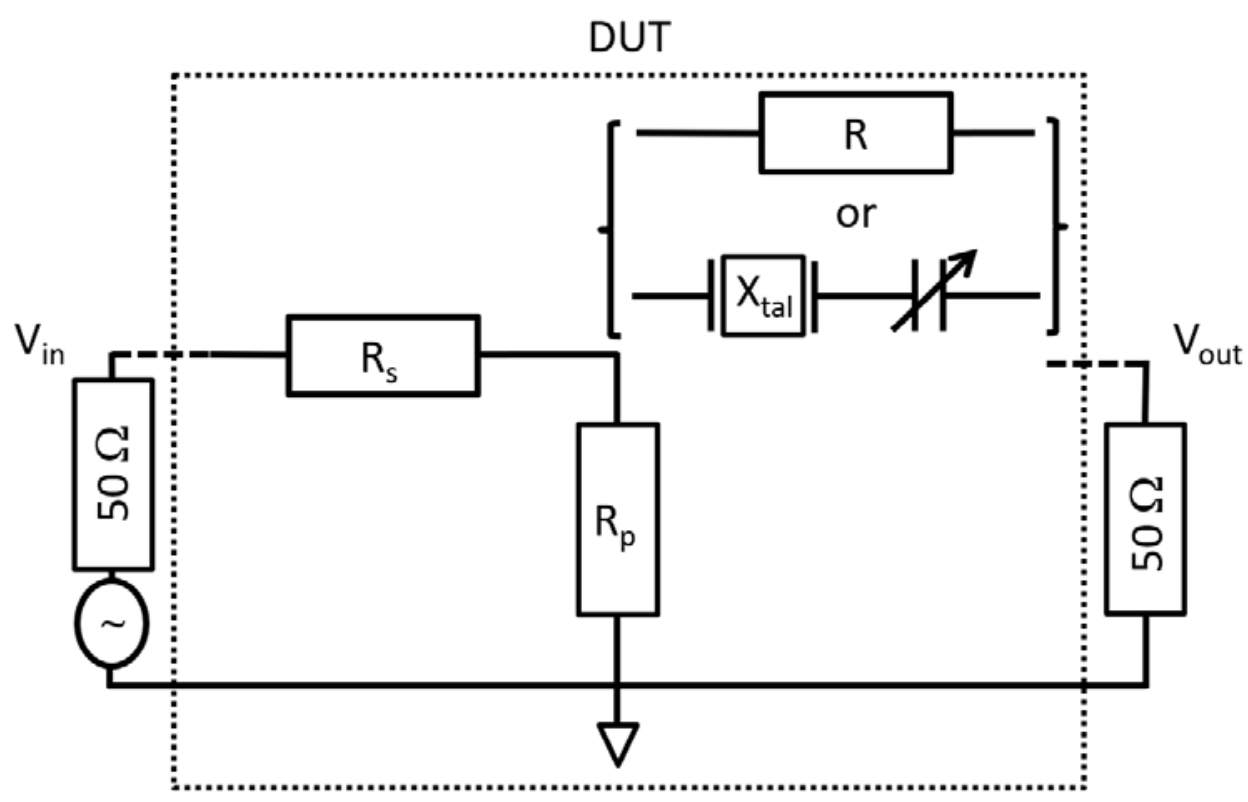

FIG. 3. Usual DUT configuration.

In the usual DUT configuration, Figure 4 presents a transfer function of a $10 \mathrm{MHz}$ quartz crystal resonator SC-cut, with a very high stability. The unloaded quality factor, $Q_{0}$, is around $1.3 \cdot 10^{6}$ and its motional resistance is $66 \Omega$. Using resistor $R_{S}$ and $R_{P}$ equal to $30 \Omega$ and $24 \Omega$ respectively the loaded quality factor, $Q_{L}$, is around $0.85 \cdot 10^{6}$ that represents about $65 \%$ of $Q_{0}$. In that case the output signal is sufficient to perform the passive noise measurement. 
Taking into account the relation between the loaded Q factor and the load impedance defined in the International Standard IEC 60444-1 17 as: $Q_{L}=\frac{\omega_{S} L_{S}}{R_{S}+R_{L}}$ with $\omega_{S}$ the serial pulsation, $\mathrm{L}_{\mathrm{S}}$ the motional inductance, $\mathrm{R}_{\mathrm{S}}$ the serial motional resistance and $\mathrm{R}_{\mathrm{L}}$ the load resistance. Table I summarizes the calculated loaded quality factor in the case of a fifty ohms resistive load.

TABLE I. Calculus of the loaded quality factor, $Q_{L}$, of the resonator loaded with $50 \Omega$.

\begin{tabular}{|c|c|c|c|c|}
\hline Motional & Unloaded Q & Load & Calculated motional inductance & Calculated loaded Q \\
resistance $\mathrm{R}_{\mathrm{S}}(\Omega)$ & factor $Q_{0}$ & resistance $(\Omega)$ & $(\mathrm{H}): L_{S}=\frac{Q_{0} R_{S}}{\omega_{S}}$ & factor: $Q_{L}=\frac{\omega_{S} L_{S}}{R_{S}+R_{L}}$ \\
\hline 66 & $1.3 \cdot 10^{6}$ & 50 & 1.365 & $739358\left(56.9 \%\right.$ of $\left.Q_{0}\right)$ \\
\hline 8 & $1 \cdot 10^{6}$ & 50 & $127.32 \cdot 10^{-3}$ & $137931\left(13.8 \%\right.$ of $\left.Q_{0}\right)$ \\
\hline
\end{tabular}

A low value of loaded Q-factor is a problem because the corner frequency will be higher and the signal level lower than at for lower frequency. This means that the measured noise could be below the noise floor of the bench. Moreover, the major inconvenience of the resistive pi network impedance matching is its dissipative effect. Therefore, when the DUT impedance is about tenth of fifty ohms, reaching a high excitation in drive level values can be difficult.

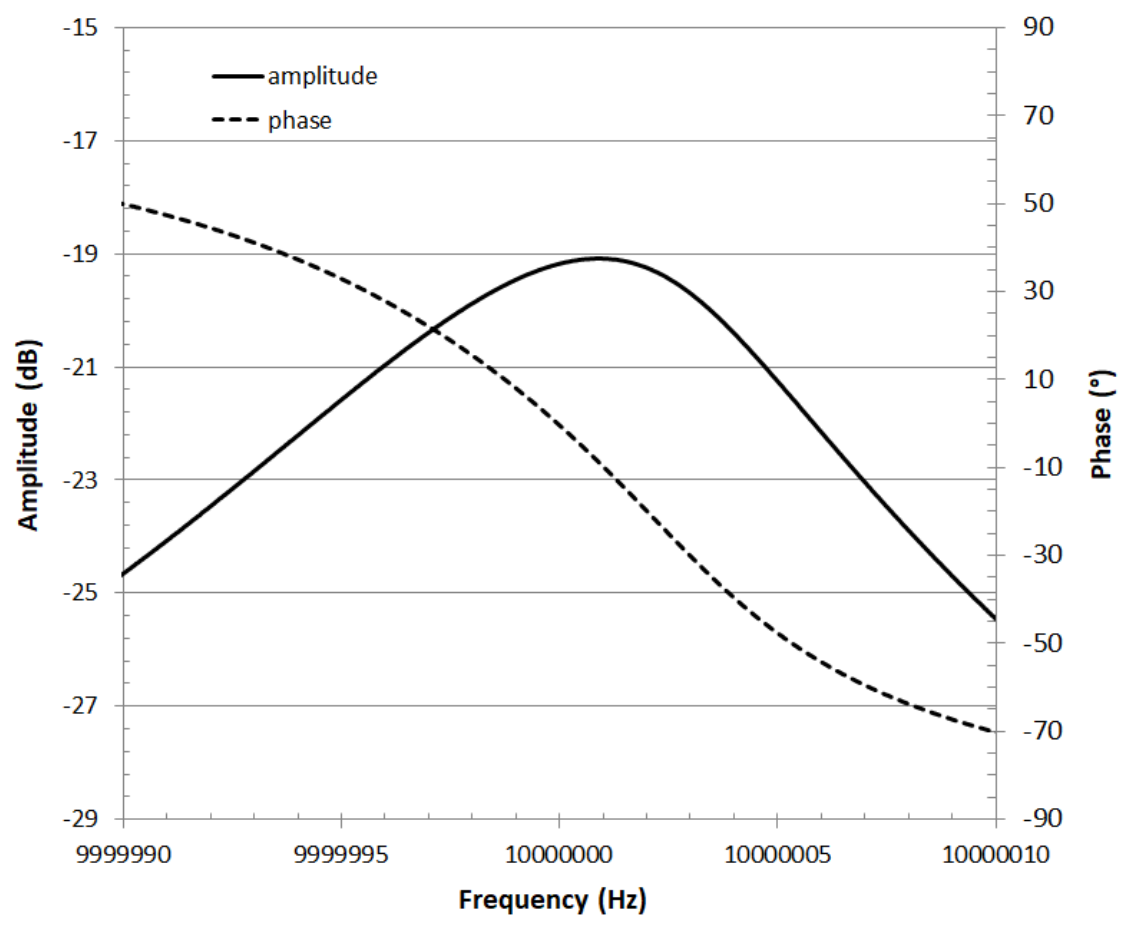

FIG. 4. Transfer function of $10 \mathrm{MHz}$ SC-cut Quartz Crystal loaded in the half bridge of figure 3. 


\section{DUT special impedance matching circuit}

The motional resistance of $10 \mathrm{MHz}$ LGT resonators is below $10 \Omega$. Thus, the loaded Q of the final mount cannot be higher than $15 \%$ of the unloaded Q in the case of classical DUT configuration (see Figure 6, with T1-1). Thus, transformer matching is proposed to improve the loaded Q factor of the resonator and maximize the drive level power. Figure 5 shows the special matching circuit.

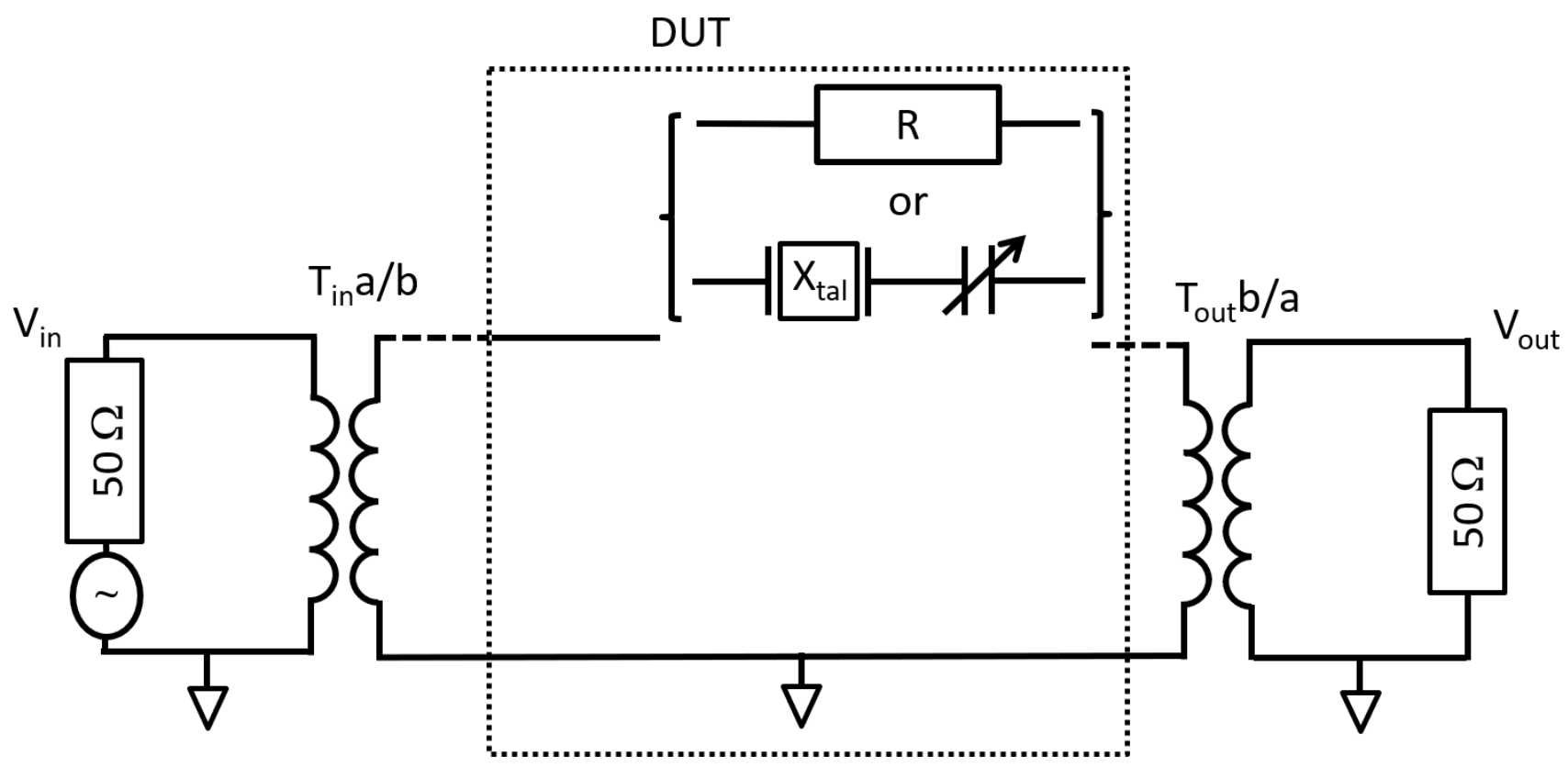

FIG. 5. Low impedance DUT configuration

Two transformers are inserted before and after the classical DUT configuration. Pspice simulations have been investigated. Figure 6 shows the magnitude and phase of the transfer function of a resonator using the circuit presented in Figure 5 . The impedance ratios of the transformers used were 1, 8 and 16. Then, the loaded Q factor of the $10 \mathrm{MHz}$ LGT resonators increased from $10 \%$ to $70 \%$, respectively. The experimental and simulated values of magnitude and phase are in a good agreement. Small shifts in frequency and phase are induced by the uncertainty in values of the tuning capacitors. 

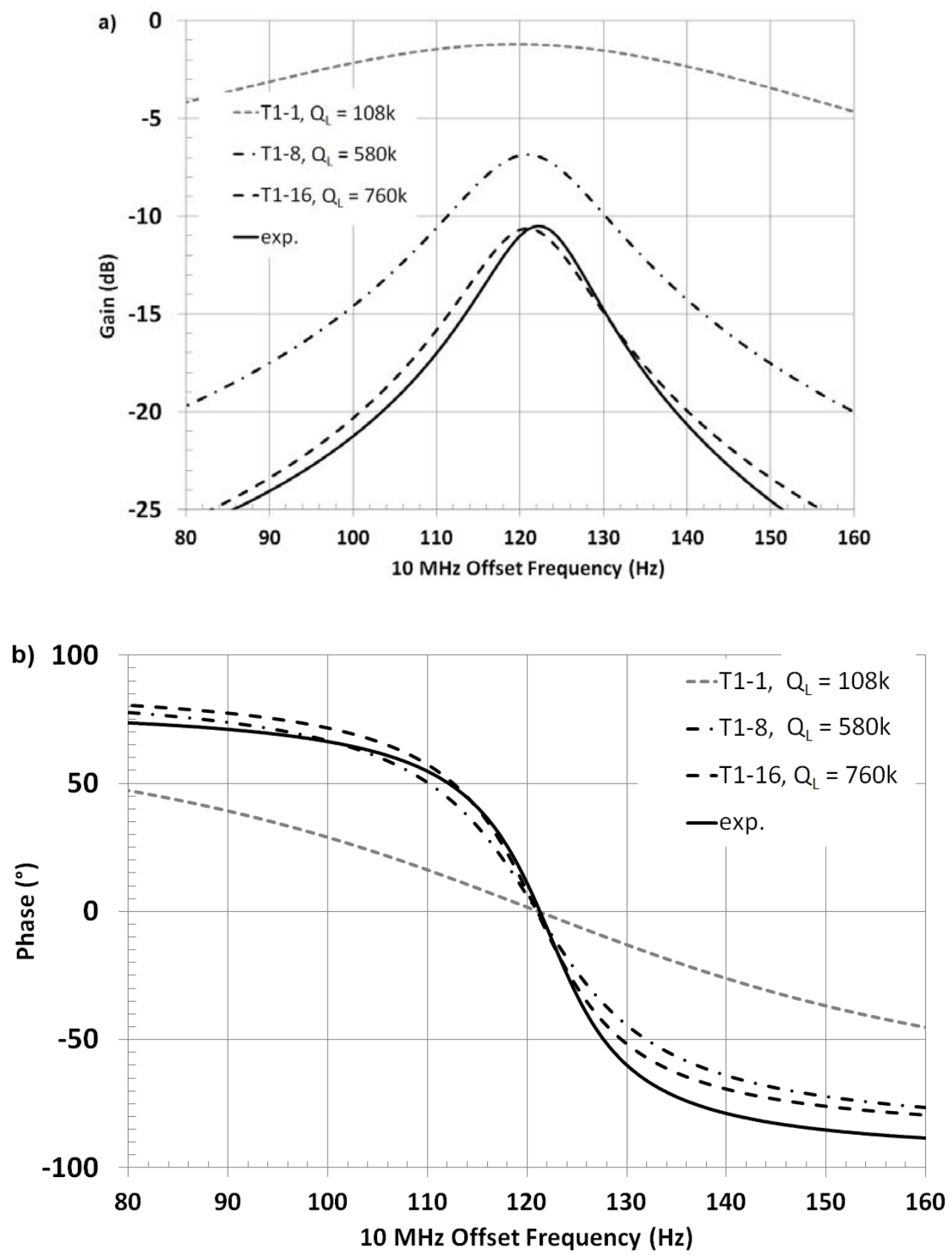

FIG. 6. Amplitude (a) and phase (b) of the transfer functions simulated with some transformer ratios compared to experimental results. The LGT resonator is simulated with $9 \Omega$ resistance.

Figure 7 presents a view of the adaptors. The two transformers are visible on the left side of the picture, the resonator is inserted inside the oven and the tuning capacitor is visible at the right side of the picture. 


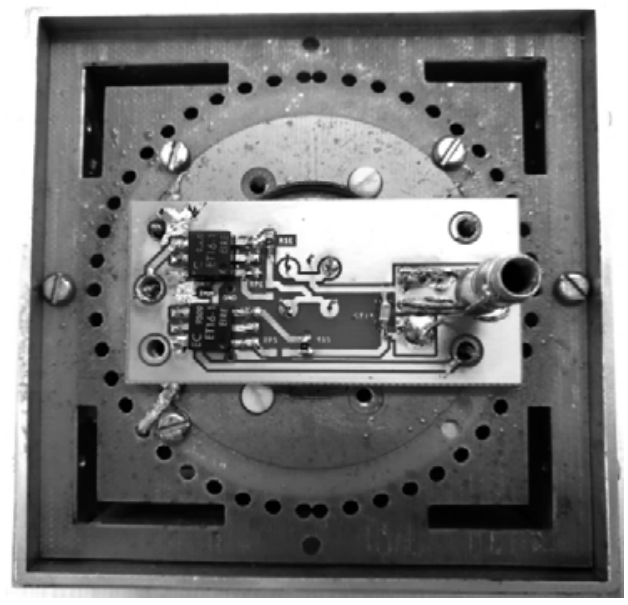

FIG. 7. Transformer adapter with two transformers, resonator inside the oven and the tuning capacitor.

To compare the impedance matching using transformer with a simple pi-bridge resistors, an optimization under Pspice was done for the same input voltage amplitudes that can be seen in Table II (with $9 \Omega$ resonators and $Q_{0}$ about $1 \cdot 10^{6}$ ). Transformer matching showed a better loaded quality factor about $80 \%$ instead of $55 \%$ obtained using a PI-network. The drive level is also higher due to lower losses.

TABLE II Comparison between transformers and PI resistive impedance matching

\begin{tabular}{|c|c|c|}
\hline & PI-network impedance matching & Transformers matching impedance ratio 1:16 \\
\hline Gain $(\mathrm{dB})$ & $-27 \mathrm{~dB}$ & $-14 \mathrm{~dB}$ \\
\hline Loaded Q-factor $(\%$ unloaded Q) & $55 \%$ & $80 \%$ \\
\hline Drive level $(\mu \mathrm{W})$ & $100 \mu \mathrm{W}$ & $94 \mu \mathrm{W}$ \\
\hline
\end{tabular}

\section{Noise floor of the bench}

Figure 8 presents the noise floor of the system using the transformer configuration according the driving power. The working frequency is set at $10.000121 \mathrm{MHz}$ to have the resonance when resonators are inserted. 


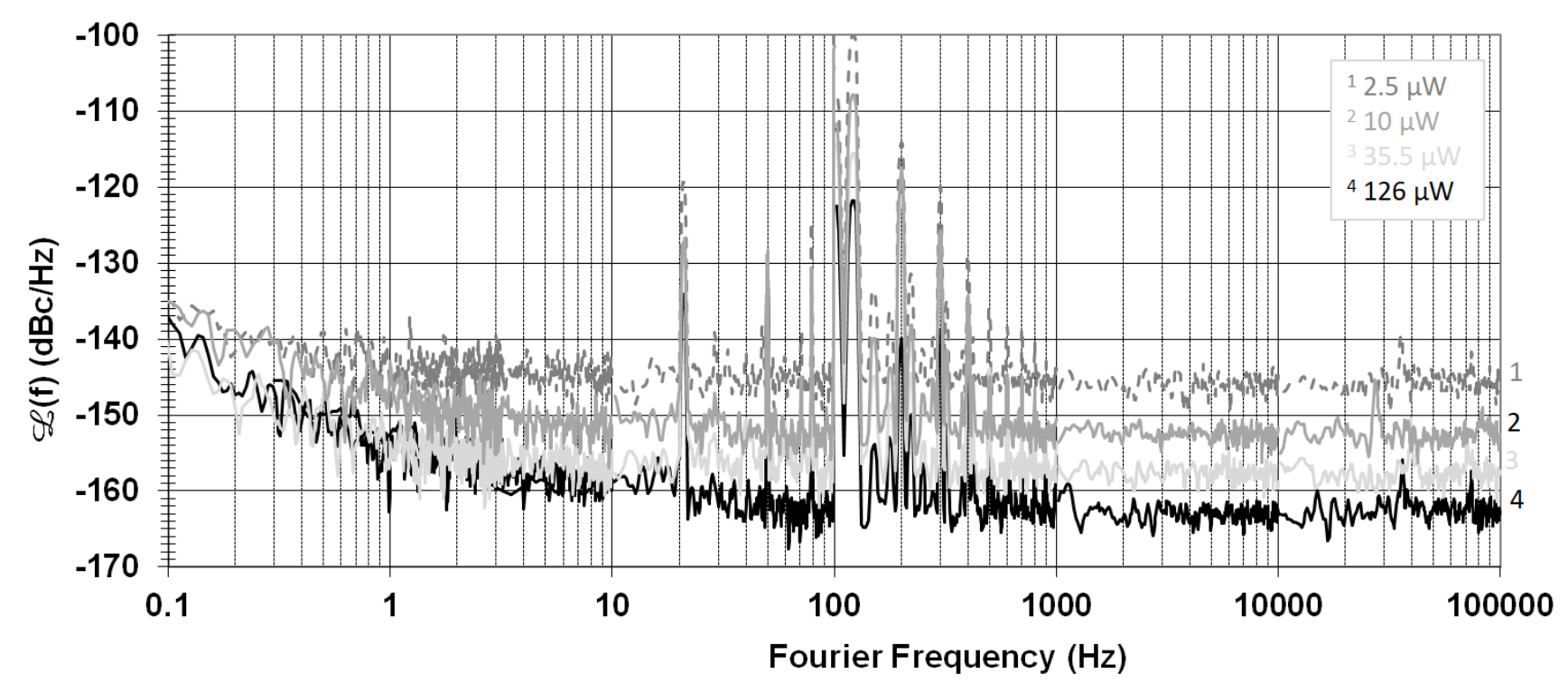

FIG. 8. Phase noise of the floor. The source frequency is $10.000121 \mathrm{MHz}$. The dissipated power is varied from 1.5 to $126 \mu \mathrm{W}$.

The noise floor of the system was achieved by inserting an equivalent resistor of $9 \Omega$ replacing the resonator. The excitation power for the resonator was varied for a range of values in micro-watts to see the effect on the phase noise floor introduced by the transformer setup as explained above. There were no unusual effects on the nature of the phase noise floor except for the level of noise floor which is a function of the input power. The noise level is below $-145 \mathrm{dBc} / \mathrm{Hz}$ at $1 \mathrm{~Hz}$. The thermal noise floor is given by the level of the dissipated power driving the DUTs (around $-156 \mathrm{dBc} / \mathrm{Hz}$ at $35.5 \mu \mathrm{W}$ ). Spurs on the curves above $10 \mathrm{~Hz}$ are because of the mixing between the frequency reference of the synthesizer at $10 \mathrm{MHz}$ and its output signal at 10.000121 MHz. In that case, a spur at $121 \mathrm{~Hz}$ can be generated. Other spurs are produced by the power supply of the system $(50,100,150 \ldots \mathrm{Hz})$. Then, mixing between the frequencies at $100 \mathrm{~Hz}$ and $121 \mathrm{~Hz}$ leads to $21 \mathrm{~Hz}$ spur and higher harmonics.

\section{NOISE MEASUREMENT ON LANGATE RESONATORS}

The measurement system presented above is used to characterize ultra-stable LGT resonators.

\section{A. Resonator characteristics}

\section{Temperature effect}

Figure 9 shows the frequency behaviors of the resonators $L G T_{(1)-(3)}$ according to temperature. Turnover temperatures are similar for all resonators and are found around $84{ }^{\circ} \mathrm{C}$. The second order dependencies are given in $\mathrm{ppb} /{ }^{\circ} \mathrm{C}^{2}$ and equal to -67.7 , -59.4 and - 72.6 for $L G T_{(1)-(3)}$, respectively. In comparison, the SC-cut type of quartz cut is six times less sensitive ${ }^{13}$. 

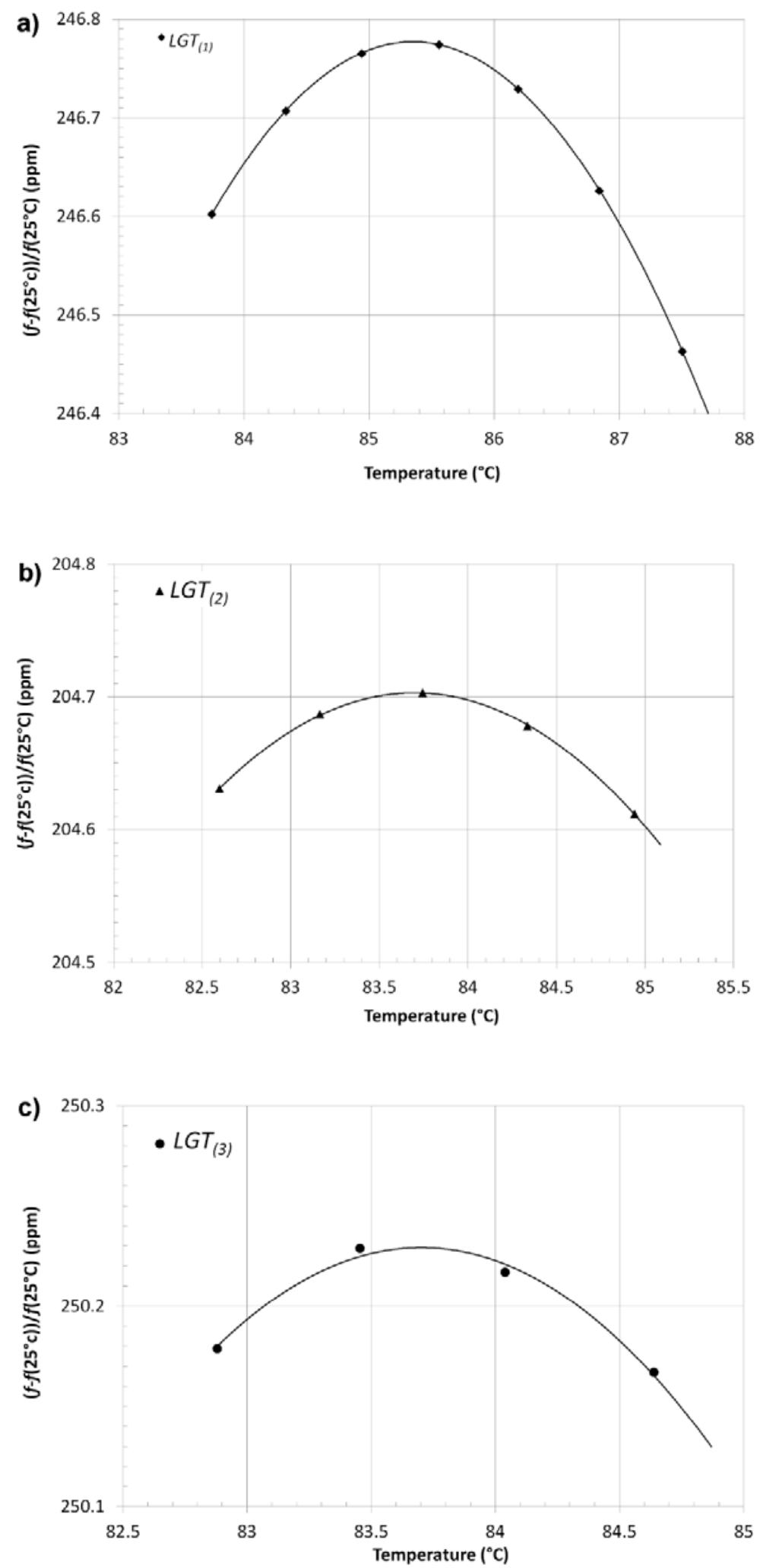

FIG. 9. Temperature parabolic curves of LGT resonators. a) resonator $L G T_{(1)}$, b) resonator $L G T_{(2)}$, c) resonator $L G T_{(3)}$. 


\section{Motional parameters}

The used crystal block is synthesized using the Czochralski method ${ }^{18}$ and comes from Cristal Innov. The LGT resonators were achieved in $\mathrm{Y}-1^{\circ}$ cut, thus, the turnover temperature is adjusted around $80^{\circ} \mathrm{C}$. The applied power to measure the motional parameters is around $60 \mu \mathrm{W}$. Figure 10 presents the amplitude and phase of the impedance according the resonant frequencies of three resonators referenced as $L G T_{(1)} L G T_{(2)}$, and $L G T_{(3)}$.

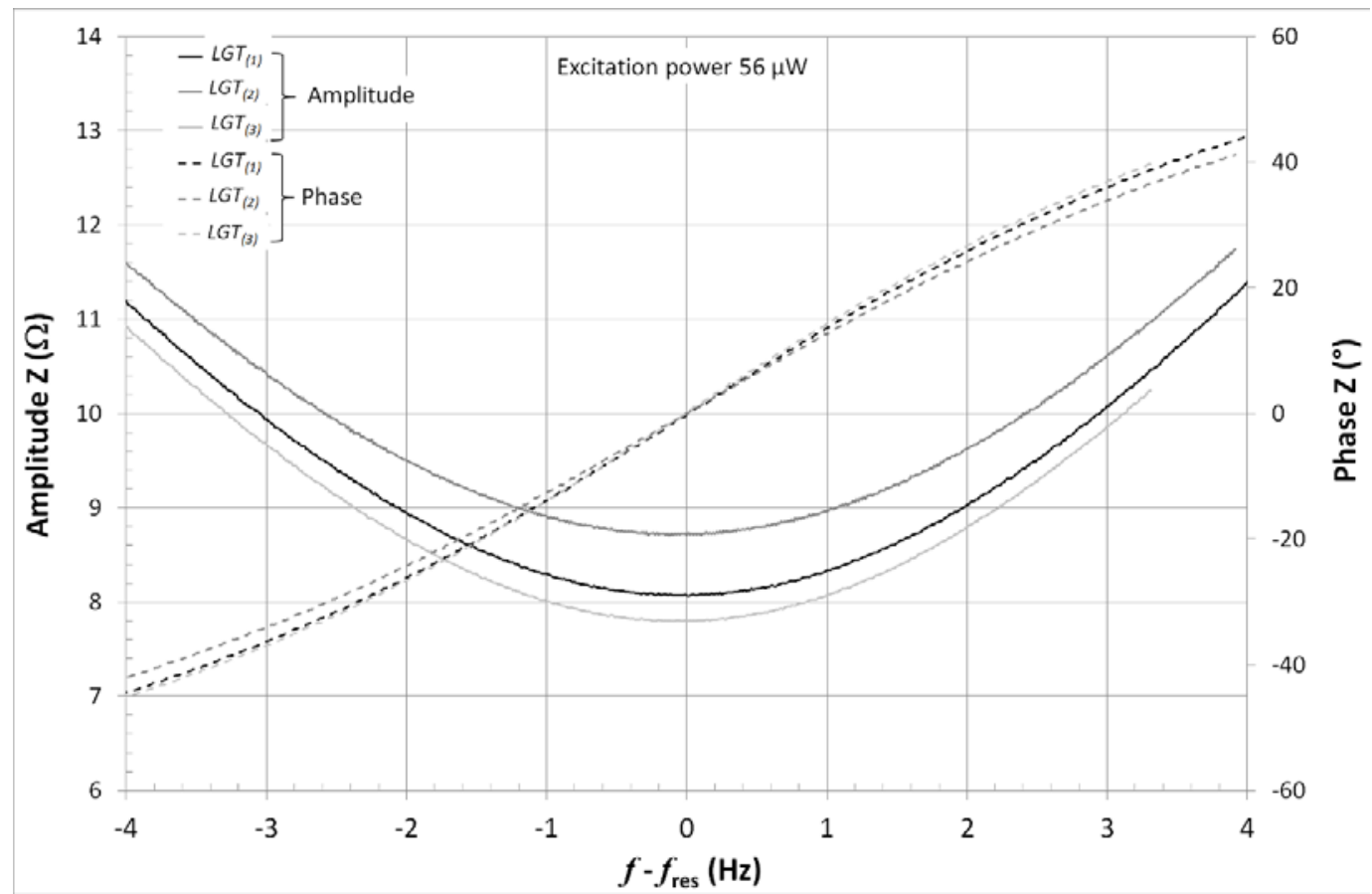

FIG. 10. Amplitude and phase of the resonators $L G T_{(1)-(3)}$, at approximately $60 \mu \mathrm{W}$ of excitation power.

Table III gives the experimental values of the resonant frequencies at turnover temperatures, the turnover temperatures PI, the motional parameters $R$ and $L$, the static capacitances $C_{0}$ and the unloaded quality factor $Q$ of the three resonators $L G T_{(1)-(3)}$ respectively. The motional resistance is given by the minimum of the amplitude of impedance. The quality factor is measured from the inverted slope of $\pm 1^{\circ}$ phase shift in Figure 10. The motional resistance was found to be around $8 \Omega$. The unloaded quality factors Q was around $1.1 \cdot 10^{6}$. 
TABLE III. Experimental values of motional parameters and quality factor.

\begin{tabular}{|l|c|c|c|c|c|}
\hline Res. & $\begin{array}{c}\boldsymbol{f}_{\text {res }}-\mathbf{1 0 ~ M H z} \\
\mathbf{( H z )}\end{array}$ & $\begin{array}{c}\boldsymbol{R} \\
(\boldsymbol{\Omega})\end{array}$ & $\begin{array}{c}\boldsymbol{L} \\
(\mathbf{m H})\end{array}$ & $\begin{array}{c}\boldsymbol{C}_{\boldsymbol{0}} \\
(\mathbf{p F})\end{array}$ & $\begin{array}{c}\boldsymbol{Q} \\
(\mathbf{1 0})\end{array}$ \\
\hline$L G T_{(1)}$ & 44.8 & 8.1 & 153 & 17.3 & 1.19 \\
\hline$L G T_{(2)}$ & 34.4 & 8.7 & 150 & 17.0 & 1.08 \\
\hline$L G T_{(3)}$ & 29.4 & 7.8 & 158 & 17.2 & 1.27 \\
\hline
\end{tabular}

\section{Driving effect}

Figure 11 shows the frequency variation of resonators $L G T_{(1)-(3)}$ according the resonator driving current. The resonator's excitation current was varied from few $\mathrm{mA}$ to $10 \mathrm{~mA}$. As observed in Kim $(2003)^{11}$, the data set of each resonator is fitted with a quadratic curve to obtain a drive sensitivity coefficient $\mathrm{D}$ defined by:

$$
\frac{\Delta f}{f}=D i^{2}
$$

The value of $\mathrm{D}$ is about $-4.2 \mathrm{ppb}$ which is a little bit higher than the values proposed in Kim (2003) ${ }^{11}$ but keeps the order of magnitude.

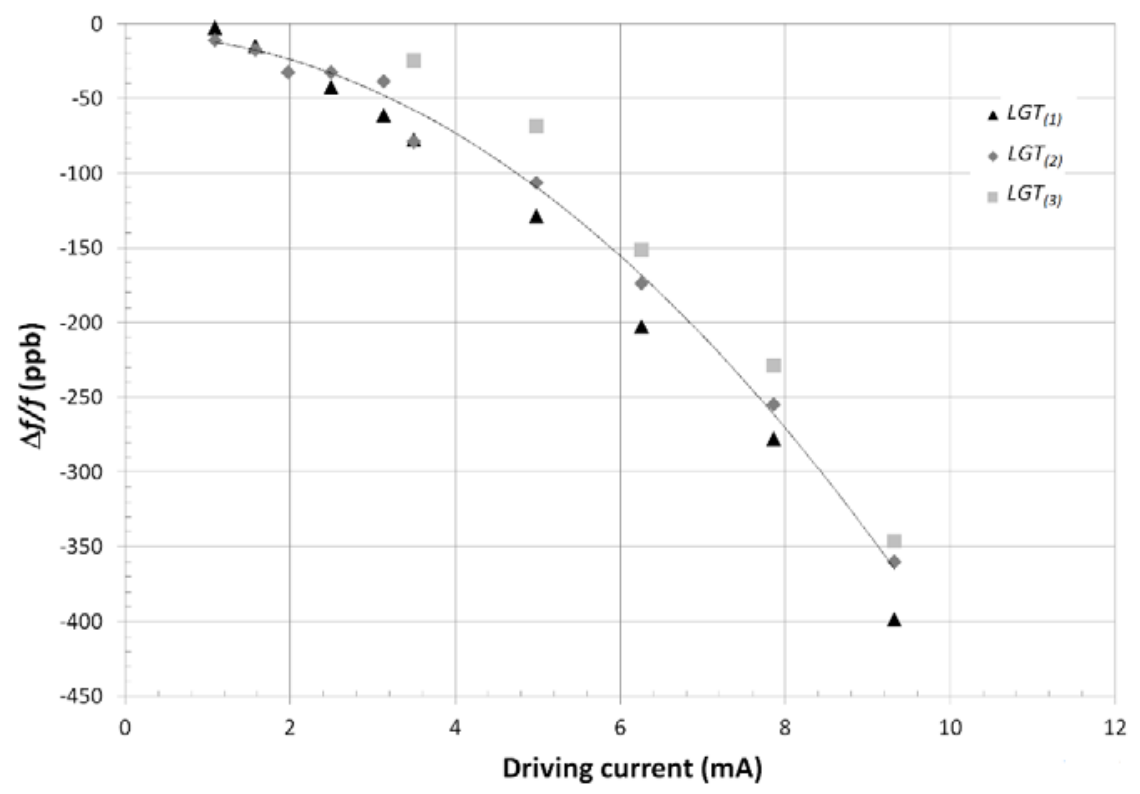

FIG. 11. Frequency variation of the resonators $L G T_{(1)-(3)}$ according to the resonator driving current. 


\section{B. Noise measurements}

Figure 12 shows the results in terms of one-sided power spectral density (PSD) of phase fluctuations, $\mathscr{L}(f)$, measured between $L G T_{(1)} L G T_{(2)}$ and $L G T_{(3)}$ resonators. The driving power of the resonator was around $200 \mu \mathrm{W}$. Figure 12a presents resonators $L G T_{(1)-(2)}$, Figure $12 \mathrm{~b} L G T_{(1)-(3)}$, Figure $12 \mathrm{c} L G T_{(2)-(3)}$. The measurements were obtained using the T1-16 transformers, hence, the loaded quality factor is optimized as presented in $\S$ B.2. The noise of the resonator is visible below $10 \mathrm{~Hz}$ Fourier frequency. Above $20 \mathrm{~Hz}$, the behavior is due to the noise floor of the measurement system.
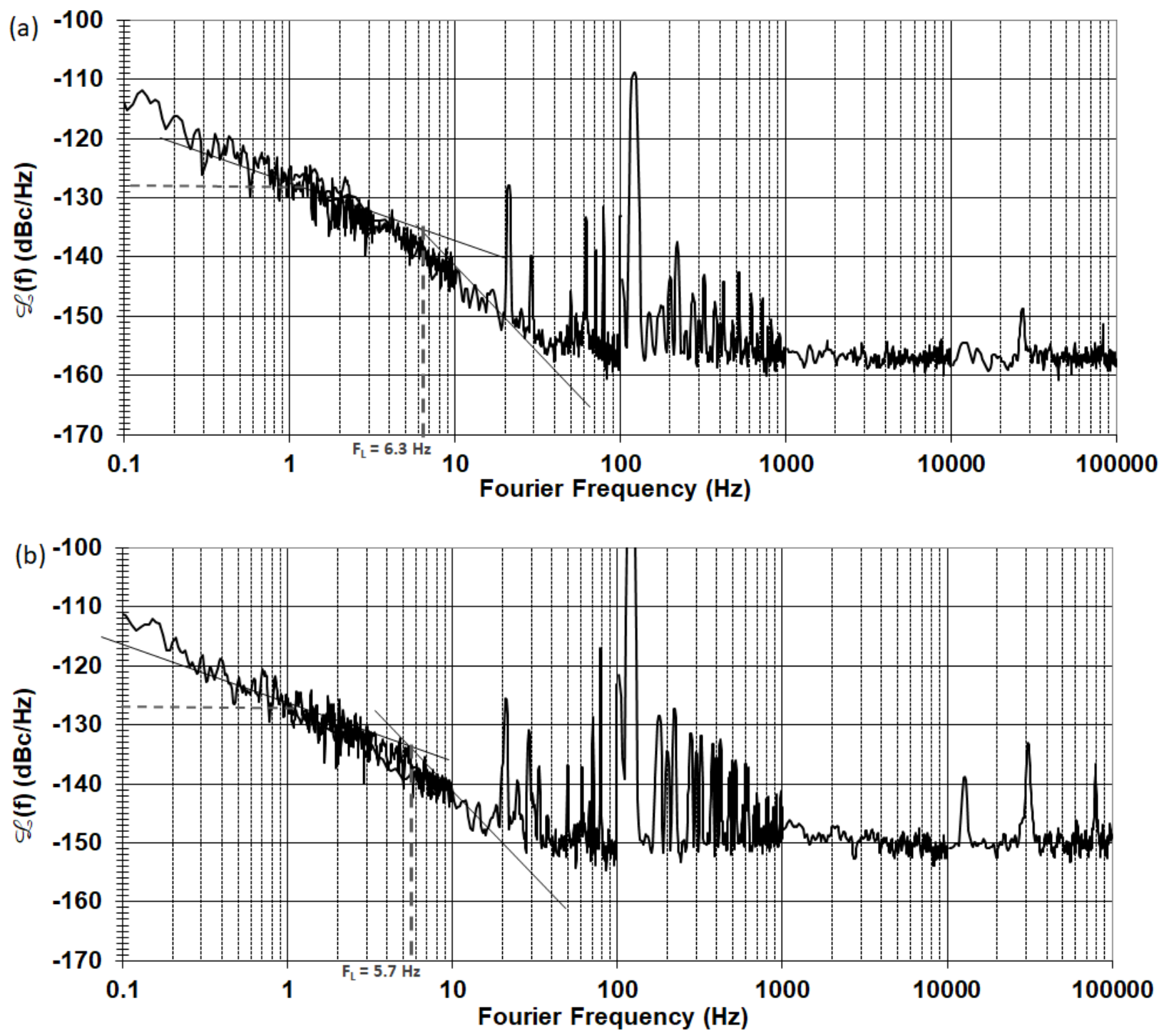


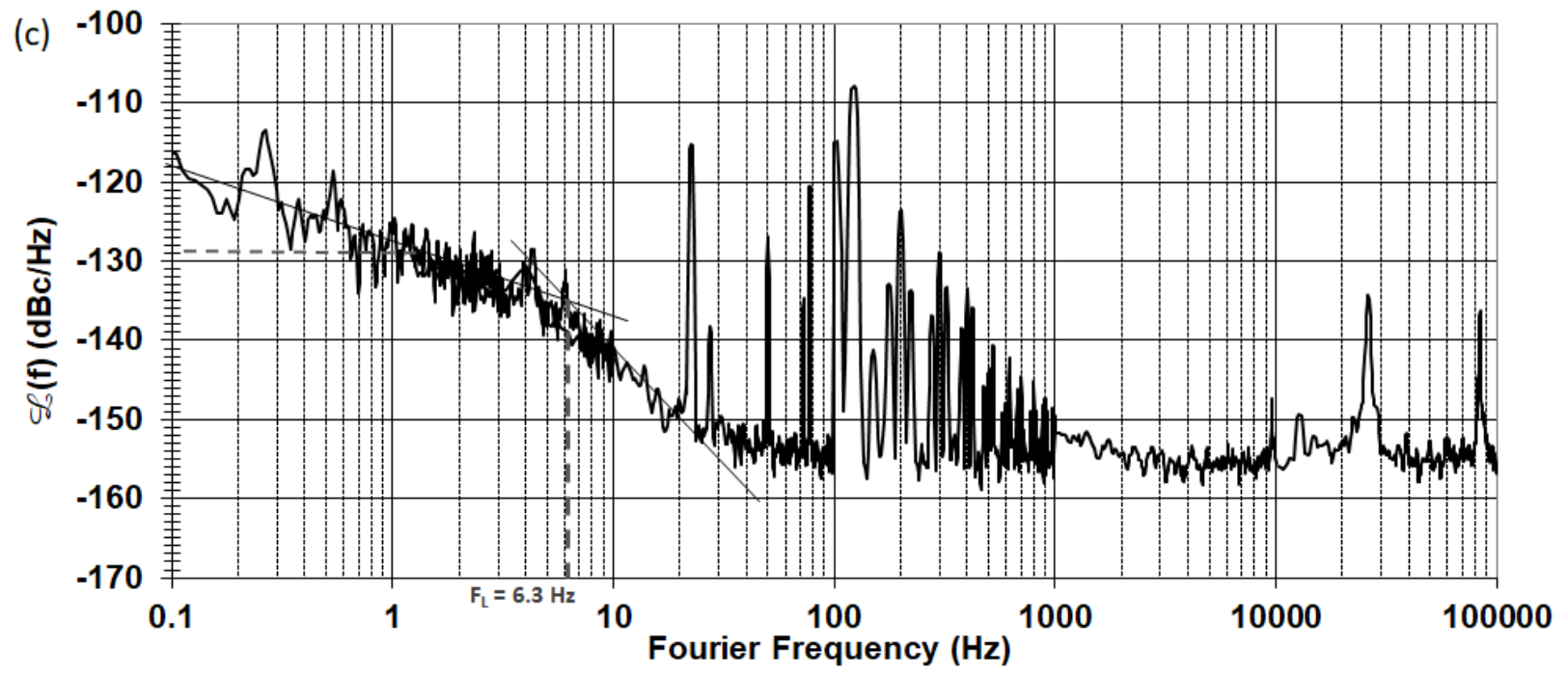

FIG. 12. Phase noise $\mathscr{L}(\mathrm{f})$ of the resonator pairs according Fourier frequencies. (a) $L G T_{(1)-(2)}$ pair, (b) $L G T_{(1)-(3)} p a i r$, (c) $L G T_{(2)-(3)}$ pair Measured with T1-16 transformers with $200 \mu \mathrm{W}$ dissipated power.

The flicker floor of the short-term stability $\sigma_{y_{-}}$floor is calculated for each pair and presented in Table IV. The optimization of the quality factor can be easily visualized by value of PSD and its asymptotic approach to determine the cut off frequency $F_{L}[8]$. The flicker floor of the short-term stability is obtained from measurements of $\mathscr{L}(1 \mathrm{~Hz})$ and the cut off frequency $F_{L}$ (Figure 12). Considering precision of the measurement system, an error $\varepsilon$ in $\sigma_{\mathrm{y}_{-} \text {floor }}$ is computed with $F_{L}$ à $\pm 0.1 \mathrm{~Hz}$ and $\mathscr{L}(1 \mathrm{~Hz})$ à $\pm 2 \mathrm{~dB}$.

TABLE IV. Short-term stability of the LGT resonators.

\begin{tabular}{|c|c|c|c|}
\hline & $\sigma_{\mathrm{y} f l o o r}-\varepsilon$ & $\sigma_{\mathrm{y} f l o o r}$ & $\sigma_{\mathrm{y} f l o o r}+\varepsilon$ \\
\hline$L G T_{(1)-(2)}$ & $2.34 \cdot 10^{-13}$ & $\mathbf{2 . 9 9 \cdot 1 0 ^ { - 1 3 }}$ & $3.82 \cdot 10^{-13}$ \\
\hline$L G T_{(1)-(3)}$ & $2.38 \cdot 10^{-13}$ & $\mathbf{3 . 0 4} \cdot 10^{-13}$ & $3.90 \cdot 10^{-13}$ \\
\hline$L G T_{(2)-(3)}$ & $2.08 \cdot 10^{-13}$ & $\mathbf{2 . 6 6} \cdot 10^{-13}$ & $3.41 \cdot 10^{-13}$ \\
\hline
\end{tabular}

Figure 13 presents the short-term stability $\sigma_{\mathrm{y}_{-} \text {floor }}$ according the power dissipated by the resonators $L G T_{(1)-(2) \text {. The measured }}$ noise level is approximately constant for a dissipated power from 10 to almost $400 \mu \mathrm{W}$. This good stability should allow to apply more power to the resonator to have a better noise floor of the oscillator. This can result in having a good phase noise close to the carrier and a good flicker floor in the oscillator and these together should be easier than in quartz crystal oscillator. 


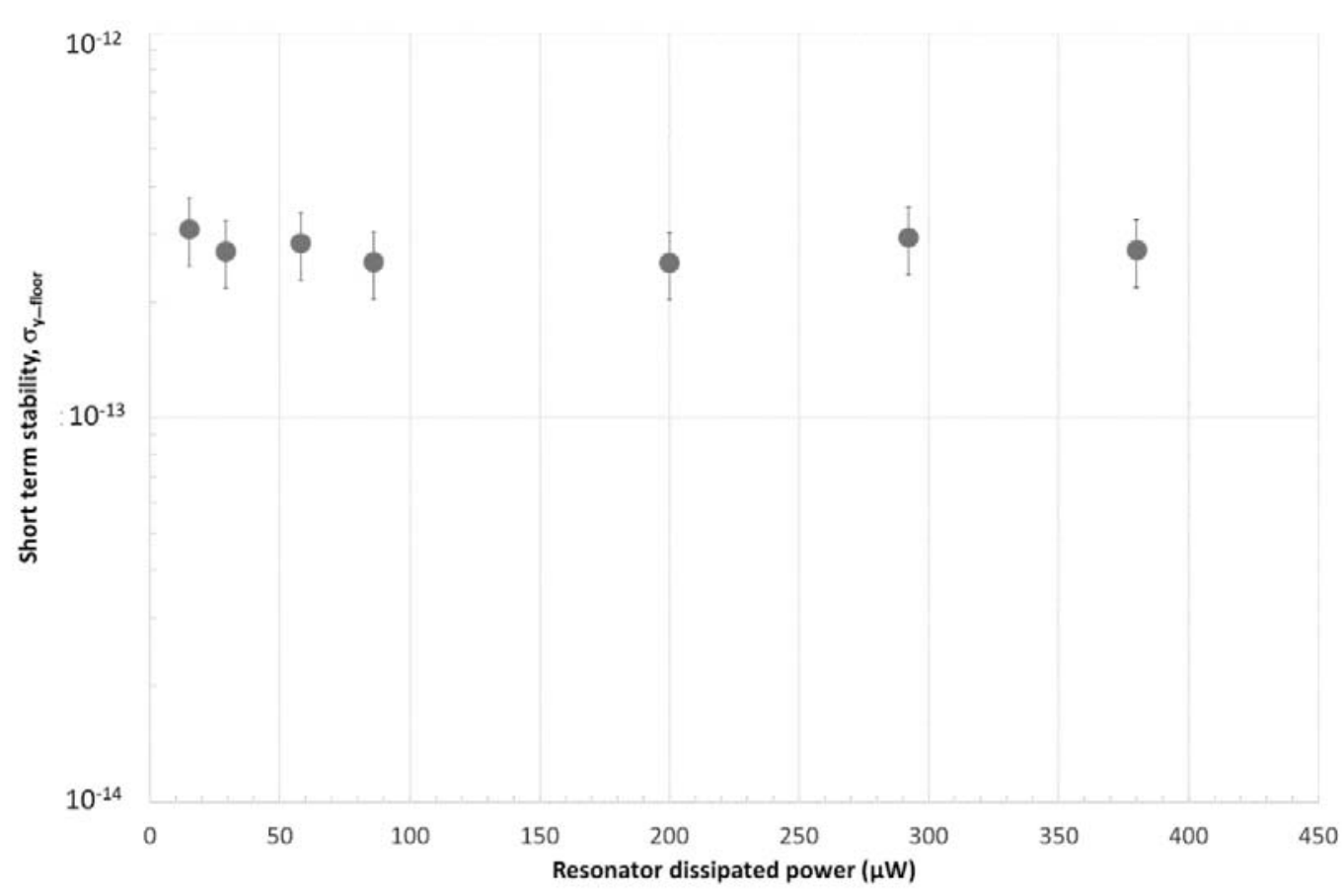

FIG. 13. Short-term stability $\sigma_{\mathrm{y}_{-} \text {floor }}$ of the resonator $L G T_{(1)-(2)}$ pair according to the resonator dissipated power.

\section{CONCLUSION}

A passive measurement system based on carrier suppression using transformers to improve the loaded quality factor of the resonators has been implemented. Transformer matching is proposed to improve the loaded Q factor of the resonator and maximize the drive level power. Hence, this specific conditioning increases the phase noise of the resonators above the noise floor of measurement system. The noise floor of the measurement system is given according to the dissipated power showing that transformers do not degrade the noise floor of the measuring bench. Short-term stability of Langatate crystal resonators has been measured through impedance matching using transformers. It is evaluated according to the resonator driving power. The good stability should allow applying more power to the resonator to have a better noise floor of the oscillator. LGT drive sensitivity is lower than in SC-cut quartz more than a factor of ten, then, has a good phase noise close to the carrier and a good flicker floor in the oscillator and these together should be easier than in quartz crystal oscillator.

\section{ACKNOWLEDGMENTS}

This work was supported by: CNES Agency, Région Bourgogne-Franche-Comté, LABEX Cluster of Excellence FIRSTTF (ANR-10-LABX-48-01), within the Program "Investissements d'Avenir" operated by the French National Research Agency 
(ANR), ANR-11-EQPX-0033-OSC-IMP, ANR-17-ERE-0002. Resonators have been achieved during ANR ASTRID ECLATEMPS (ANR-12-ASTR-0030-01).

\section{DATA AVAILABILITY}

The data that supports the findings of this study are available from the corresponding author upon reasonable request. 


\section{REFERENCES}

${ }^{1}$ K. H. Sann, (1968), “The measurement of near-carrier noise in microwave amplifiers,” IEEE Trans. Microwave Theory Tech., MTT-16, 761. https://doi.org/10.1109/TMTT.1968.1126783.

${ }^{2} \mathrm{C}$. H. Horn, (1969), “A carrier suppression technique for measuring $\mathrm{S} / \mathrm{N}$ and carrier/sideband ratios greater than $120 \mathrm{~dB}$," in Proceeding of the 23rd Annual Frequency Control Symposium, Atlantic City, Electronic Industries Association Washington, D.C., pp. 6-8. https://doi.org/10.1109/FREQ.1969.199765.

${ }^{3}$ F. L. Walls, (1997), "Suppressed carrier based PM and AM noise measurement techniques," in Proceeding of the 51 ${ }^{\text {st }}$ Annual Frequency Control Symposium, Orlando, Institute of Electrical and Electronics Engineer Inc., Piscataway, NJ, pp. 485-492. https://doi.org/10.1109/FREQ.1997.638647.

${ }^{4}$ E. N. Ivanov, M. E. Tobar and R. A. Woode, (1997), “A study of noise phenomena in microwave components using an advanced noise measurement system,” IEEE Trans. Ultrason. Ferroelect. Freq. Contr., 44, 161. https://doi.org/10.1109/58.585211.

${ }^{5}$ E. Rubiola, V. Giordano and J. Groslambert, (1999), "Very high frequency and microwave interferometric phase and amplitude noise measurements,” Rev. Sci. Instrum., 70, 220. https://doi.org/10.1063/1.1149351.

${ }^{6}$ E. Rubiola, J. Groslambert, M. Brunet, and V. Giordano, (2000), "Flicker noise measurement of HF quartz resonators," IEEE Trans. Ultrason. Ferroelectr. Freq. Contr., 47, 361. https://doi.org/10.1109/58.827421.

${ }^{7}$ F. Sthal, M. Mourey, F. Marionnet, and W. F. Walls, (2000), "Phase noise measurements of 10 MHz BVA quartz crystal resonator,” IEEE Trans. Ultrason. Ferroelectr. Freq. Contr., 47, 369. https://doi.org/10.1109/58.827422.

${ }^{8}$ F. Sthal, J. Imbaud, X. Vacheret, P. Salzenstein, G. Cibiel and S. Galliou, (2013), "Computation method for the short-term stability of quartz crystal resonators obtained from passive phase noise measures,” IEEE Trans. Ultrason. Ferroelectr. Freq. Contr., 60, 1530. https://doi.org/10.1109/TUFFC.2013.2725.

${ }^{9}$ F. Sthal, M. Devel, J. Imbaud, R. Bourquin and G. Cibiel, (2015), "Fluctuation-dissipation theorem and 1/f noise of bulk acoustic wave cavities,” Appl. Phys. Lett., 107, 103502. https://doi.org/10.1063/1.4930167. 
${ }^{10}$ F. Sthal, M. Devel, J. Imbaud, R. Bourquin, S. Ghosh and G. Cibiel, (2016), "Study on the origin of 1/f noise in quartz resonators,” J. Stat. Mech., 6, 054025. https://doi.org/10.1088/1742-5468/2016/05/054025.

${ }^{11}$ Y. Kim, (2003), “Amplitude-frequency effect of Y-cut Langanite and Langatate,” IEEE Trans. on Ultrason., Ferroelect. and Freq. Contr., vol. 50, 1683, December. https://doi.org/10.1109/TUFFC.2003.1256309.

${ }^{12}$ J. Imbaud, S. Galliou, J.P. Romand, P. Abbé, and R. Bourquin, (2008), “Development of a 10 MHz oscillator working with an LGT crystal resonator: Preliminary results," IEEE Trans. Ultrason. Ferroelec. Freq. Contr., $55,1913$. https://doi.org/10.1109/TUFFC.883.

${ }^{13}$ J. Imbaud, G. Douchet and F. Sthal, (2010), "Passive noise analyses on langatate crystal resonators," in Proceeding of the IEEE Int. Freq. Cont. Symp., Newport beach, The Printing House, Inc., pp. 419-424. https://doi.org/10.1109/58.827422.

${ }^{14}$ J. Imbaud, J. J. Boy and F. Sthal, (2014), "LGT alternative quartz materials for ultra-stable oscillators," in Proceeding of the Proc.IEEE Int. Freq. Contr. Symp., Taipei, Tawain, IEEE Service Center, Piscataway, NJ, pp.32-39. https://doi.org/10.1109/FCS.2014.6859848.

${ }^{15}$ F. Sthal, S. Galliou, P. Abbé, X. Vacheret, and G. Cibiel, (2007), "Ultra-stable crystal ovens and simple characterization," Electron. Lett., 43, 900. https://doi.org/10.1049/el:20071052.

${ }^{16}$ N. Vorobyev, J. Imbaud, P. Abbé and F. Sthal, (2015), “Ultra-stable digitally controlled oven,” Rev. Sci. Instrum., 86, 026102. https://doi.org/10.1063/1.4907542.

${ }^{17}$ IEC Standard, (1999), "Measurement of quartz crystal unit parameters by zero phase technique in a pi-network,” IEC 604441:1986 + A1:1999, International Electrotechnical Commission, Paris.

${ }^{18}$ B. Boutahraoui, A. Nehari, J.J. Boy, X. Vacheret, M. Allani, H. Cabane, M. Dumortier, M. Derbal, K. Lebbou, "LGT $\left(\mathrm{La}_{3} \mathrm{Ga}_{5.5} \mathrm{Ta}_{0.5} \mathrm{O}_{14}\right)$ langatate bulk crystal grown from the melt by Czochralski technique and characterization," Optical Materials, (2017), Vol. 65, March, pp. 103-105, https://doi.org/10.1016/j.optmat.2016.09.018. 